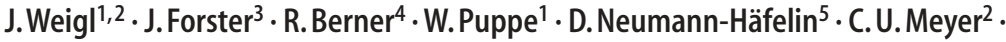

F.Zepp ${ }^{2} \cdot$ H.J.Schmitt ${ }^{2}$

${ }^{1}$ Pädiatrische Infektiologie, Klinik für Allgemeine Pädiatrie, CAU Kiel

${ }^{2}$ Kinderklinik, Pädiatrische Infektiologie \& Zentrum Präventive Pädiatrie, JGU Mainz

${ }^{3}$ St. Josephkrankenhaus, Abteilung für Kinderheilkunde und Jugendmedizin St. Hedwig, Freiburg

${ }^{4}$ Bakteriologisches Labor, Universitätskinderklinik, ALU Freiburg

${ }^{5}$ Abteilung Virologie, Institut für Medizinische Mikrobiologie und Hygiene, ALU Freiburg

\title{
Virale Atemwegsinfektionen mit saisonaler Häufung bei Kindern
}

\section{Eine Übersicht mit Schwerpunkt auf Daten aus Deutschland}

\section{Zusammenfassung}

Akute Atemwegsinfektionen (ARI) haben eine herausragende Bedeutung in der Pädiatrie. Neben der hohen Inzidenz im ambulanten Bereich spielen vor allem Hospitalisationen und eventuelle Spätfolgen eine gewichtige Rolle. Sowohl das Krankheitsspektrum als auch das Erregerspektrum sind sehr weit. Individuelle Faktoren, wie z. B. die altersspezifische Immunität und epidemiologische Einflussgrößen, bedingen die zentrale Rolle von Kindern in der Epidemiologie von ARl in der Gesamtpopulation. Nachdem es lange Zeit keine präzisen, Erreger-spezifischen Daten für Deutschland gab, wurden in den letzten Jahren zu mehreren Erregern epidemiologische Daten publiziert. Die populationsbezogenen Inzidenzen für ambulant erworbene Pneumonien, RSV- und Influenza-positive Hospitalisationen lagen dabei im Niveau unserer Nachbarländer und den USA. Auch die Epidemiologie von Parainfluenza-, Adeno- und Enteroviren scheint der dort beschriebenen zu entsprechen. Präzise Daten sind insbesondere wichtig für Maßnahmen im öffentlichen Gesundheitswesen, wie z. B. für die Planung und Prioritätensetzung bei Impfempfehlungen. Ein webbasiertes Frühwarnsystem, organisiert vom Bundesministerium für Bildung und Forschung (BMBF) geförderten Netzwerk PID-ARI.Net (pediatric infectious diseases acute respiratory tract infections network), soll die Ärzteschaft laufend über die aktuelle Epidemiologie dieser Erreger informieren.
Schlüsselwörter

Akute Atemwegsinfektionen - Influenzaviren . Parainfluenzaviren · Picornaviren .

PID-ARI.Net · Respiratory Syncytial Virus · Web

\section{Bedeutung akuter Atemwegs- infektionen: Burden of disease}

Akute Atemwegsinfektionen (ARI) haben nach wie vor weltweit den größten Anteil an gesundheitspolitisch relevanten Infektionskrankheiten [1]. In Entwicklungsländern haben ARI zudem den höchsten Anteil an der Kindersterblichkeit. Im Jahre 1994 wurde die Zahl der Todesfälle durch ARI für Kinder unter 5 Jahren auf 4,3 Millionen (90/1.00o Kinderjahre) geschätzt $[2,3]$. In Deutschland stellen Todesfälle durch ARI eher eine Ausnahme dar und betreffen meistens Patienten mit schweren Grundkrankheiten. Fortgeschrittene Atemwegsinfektionen im Kindesalter bedürfen jedoch einer stufenweisen adjuvanten Behandlung, die von der klinischen Überwachung (Pulsoximeter) über die Gabe von Sauerstoff bis hin zur maschinellen Beatmung gehen kann. Auch wenn bei uns Todesfälle durch ARI eine geringere Rolle spielen als in unterentwickelten Ländern, so sind ARI durchaus für unsere Bevölkerung und unser Gesundheitssystem von Bedeutung (Abb.1).
Hospitalisationen, als realistisches Maß für schwere ARI im Kindesalter in Deutschland, sind sowohl einschneidend für das Kind und die Familie, als auch gesundheitsökonomisch bedeutend. Die Hospitalisierungsraten, z.B. für Pneumonie [4], RSV (Respiratory Syncytial-Virus) [5] und Influenza-assoziierte Erkrankungen [6], liegen in Deutschland gleich hoch wie in anderen Ländern mit vergleichbarergeographischer Breiteund wirtschaftlichem und sozialem Niveau. Auch im ambulanten Bereich ist die Belastung unseres Gesundheitswesens durch ARI beträchtlich. Laut Daten der Arbeitsgemeinschaft Influenza (AGI) [7] sind $20-25 \%$ der Besuche beim Kinderarzt und $7-10 \%$ derjenigen beim Allgemeinarzt durch ARI bedingt. Da die ARIKrankheitsbilder im Hinblick auf ihre Ätiologie relativ unspezifisch sind (je jünger um so unspezifischer), werden häufig Antibiotika bei meist viral bedingten Erkrankungen eingesetzt, was brisante Folgen für die Prävalenz von Antibiotikaresistenzen hat.

\footnotetext{
C) Springer-Verlag 2003

Dr.Josef Weigl

Pädiatrische Infektiologie, Klinik für Allgemeine Pädiatrie, Kiel,

Schwanenweg 20,24105 Kiel,

E-Mail: weig@@pediatrics.uni-kiel.de
} 
Bundesgesundheitsbl - Gesundheitsforsch Gesundheitsschutz 2003 4 46:9-19

DOI 10.1007/s00103-002-0543-8

J.Weigl · J. Forster $\cdot$ R. Berner $\cdot$ W. Puppe

D. Neumann-Häfelin · C.U.Meyer · F.Zepp

H.J.Schmitt

Seasonal occurrence of viral respiratory tract infections in children

\section{Abstract}

Acute respiratory tract infections (ARI) contribute the highest burden of disease in children to date. Besides the high incidence in outpatients, ARI are important causes of hospital admission and possibly chronic disease. There are numerous diseases as well as numerous pathogens. Individual risk factors such as the age-specific immunity and epidemiological variables determine the high disease burden. Children also play a key role in the epidemiology in the referring total population. There were no precise, pathogen-specific data so far for Germany, but epidemiologic data on several airway viruses were published recently. The population-based incidence of community-acquired pneumonia, RSV- and Influenza-positive hospitalizations was in the same range as reported from neighborhood countries and the US. Also the epidemiology of parainfluenza-, adeno- and enteroviruses seems to be very similar to these countries. Precise data are important for individual care as well as intervention strategies in public health, such as the planning and priority setting of immunization recommendations. A newly created webbased early warning system organized by the network PID-ARI.Net sponsored by the German Ministry for Education and Research (BMBF) is expected to keep the medical community up to date on these pathogens.

\section{Keywords}

Acute airway infections · Influenza virus . Parainfluenza virus · Picornaviruses . PID-ARI.Net · Respiratory syncytial virus • Web

\section{Leitthema: Atemwegsinfektionen bei Kindern und Erwachsenen}

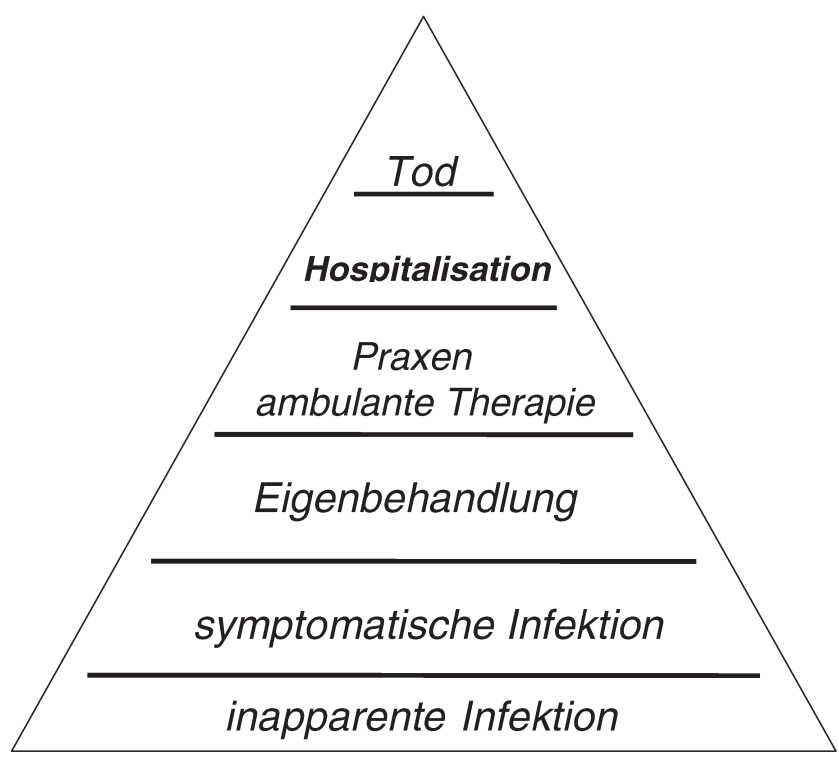

Reservoir

Abb. 1 Eisberg akuter Atemwegsinfektionen

In den letzten Jahren wurde bei Kindern bis zum Schulalter zunehmend über Spätfolgen nach Hospitalisierung wegen RSV-positiver, tiefer Atemwegsinfektionen (LRI) berichtet; insbesondere über eine Beeinträchtigung der Lungenfunktion mit Asthmaneigung [8]. In weiteren Studien variierten die Befunde von einer schon nach der Rekonvaleszenz unauffälligen Lungenfunktion [9] über mittelfristige Einbußen [10] bis zu den vorgenannten langfristigen Veränderungen. Deutsche Kinder, die nicht hospitalisiert waren, erlebten nach RSV-Infektion keine häufigere allergische Sensibilisierung [11]. Daten über langfristige Effekte weiterer häufiger ARI-Erreger liegen kaum vor. Sie sind jedoch notwendig für einen rationalen Versorgungsplan und die Einschätzung des Wertes von Präventionsmaßnahmen, speziell von Impfungen.

\section{„Die Belastung des Gesundheits- wesens durch akute Atemwegs- infektionen ist beträchtlich."}

Der Erforschung der Epidemiologie der Atemwegsinfektionen wurde in den letzten Jahren ein hoher Stellenwert eingeräumt, so dass das BMBF ein Forschungsnetzwerk (PID-ARI.Net) und die Industrie ein Netzwerk (PRI.DE) finanzierte. Weitere Projekte anderer Arbeitsgruppen befassen sich mit engeren Fragestellungen für Untergruppen von Patienten.

\section{Durch Atemwegsviren bedingte Krankheitsformen}

Die Anzahl der Atemwegserreger ist sehr groß. So gibt es z. B. über 100 Arten von Rhinoviren und 42 Arten von Adenoviren, von denen mehrere ARI verursachen können. Tabelle 1 zeigt einen Überblick. In der Tabelle sind auch die bakteriellen Erreger mit aufgeführt, weil sich die Krankheitsbilder deutlich überlappen und dies, wie oben dargestellt, zu einem hohen Antibiotikaverbrauch führt. Dazu kommt noch ein diagnostisches Dilemma (s.u.). Die LRI, kombiniert mit jungem Alter und/oder einer Grundkrankheit, führen zu dem Segment der Population, das überwiegend hospitalisiert werden muss (s. Abb. 1). Die klassischen Krankheitsbilder dabei sind die Laryngotracheobronchitis (LTB), die Bronchitis, die Bronchiolitis oder obstruktive Bronchitis und die Pneumonie, mit oder ohne bronchiale Obstruktion. Nachdem die Begriffsfassung der Bronchiolitis von Ort zu Ort uneinheitlich ist, sollte nur der Begriff obstruktive Bronchitis zur Anwendung kommen [12].

\section{Diagnostisches Dilemma}

Bis heute gibt es kein Routineverfahren zur mikrobiologischen Diagnostik von bakteriellen LRI bei Kindern (Abb. 2). Nachdem viele, potenziell pathogene, Bakterien auch die oberen Atemwege be- 
Tabelle 1

Krankheitsbilder und Erreger akuter Atemwegsinfektionen

\begin{tabular}{|c|c|c|c|c|c|c|c|c|c|}
\hline Erreger & $\begin{array}{l}\text { Kolonisator } \\
\text { (Exkretion) }\end{array}$ & Erkältung & $\begin{array}{l}\text { Otitis media } \\
\text { Sinusitis }\end{array}$ & $\begin{array}{l}\text { Tonsillitis } \\
\text { Pharyngitis }\end{array}$ & $\begin{array}{l}\text { Epiglottitis } \\
\text { Tracheitis }\end{array}$ & $\begin{array}{l}\text { Laryngotracheo- } \\
\text { bronchitis }\end{array}$ & Bronchitis & Bronchiolitis & Pneumonie \\
\hline \multicolumn{10}{|l|}{ Viren } \\
\hline RSV & - & ++ & ++ & + & & ++ & +++ & ++++ & +++ \\
\hline Influenza $A, B, C$ & - & + & +++ & ++ & & ++ & +++ & + & ++ \\
\hline Parainfluenza 1 & - & ++ & + & ++ & & +++ & ++ & + & ++ \\
\hline Parainfluenza 2 & - & ++ & + & ++ & & ++ & ++ & + & ++ \\
\hline Parainfluenza 3 & - & & + & ++ & & +++ & +++ & +++ & ++ \\
\hline Parainfluenza 4 & - & & & ++ & & + & + & + & + \\
\hline Adenoviren & $(+)$ & + & + & 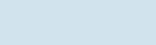 & & +++ & +++ & + & ++ \\
\hline Enteroviren & $(+)$ & + & + & ++ & & + & + & + & + \\
\hline Rhinoviren & - & ++++ & ++ & + & & ++ & ++ & + & + \\
\hline Coronaviren & - & ++ & & & & & & & + \\
\hline Reoviren & - & + & & + & & & & & \\
\hline hMPV & - & & & & & & + & ++ & ++ \\
\hline \multicolumn{10}{|l|}{ Bakterien } \\
\hline S.pneumoniae & + & - & +++ & & ++ & & & & ++++ \\
\hline H. influenzae $b$ & + & - & +++ & & ++++ & & & & +++ \\
\hline H. infl. non b & + & - & + & & + & & & & + \\
\hline M. catarrhalis & + & - & ++ & & & & & & \\
\hline S. pyogenes & + & - & + & ++++ & ++ & & & & + \\
\hline S. aureus & + & - & + & & ++ & & & & ++ \\
\hline N. meningitidis & + & - & - & & & & & & + \\
\hline B. pertussis & - & + & & & & & ++ & & + \\
\hline B. parapertussis & - & + & & & & & + & & \\
\hline M.pneumoniae & - & + & + & + & & & +++ & + & +++ \\
\hline C.pneumoniae & $(+)$ & & & + & & & + & & + \\
\hline Legionella spp. & - & - & & + & & & & & + \\
\hline
\end{tabular}

RSV respiratorisches Syncytialvirus, hMPV humanes Metapneumovirus, Zusammenstellung nach Literatur und eigenen Daten (J. Weigl).

siedeln, lassen Proben (Abstriche oder Absaugsekrete) aus den oberen Atemwegen nur eine Aussage zur Kolonisierung mit derartigen Erregern zu (s. Tabelle 1). Nur für Erreger, die die oberen Atemwege nicht besiedeln und somit nur bei Erkrankten dort vorhanden sind, lässt das synchrone Zusammentreffen einer LRIDiagnose mit dem Nachweis eines entsprechenden Erregers (meist Atemwegsviren) einen ätiologischen Teilschluss zu. Nachdem aber kolonisierende bakterielle Erreger nicht kausal-ätiologisch zugeordnet bzw. ausgeschlossen werden können, bleibt immer offen, inwieweit eine viral-bakterielle Koinfektion vorliegen könnte. Aus diesem Grund darf deshalb während der ganzen Diskussion um virale Atemwegsinfektionen nie vergessen werden, dass eine deutliche diagnostische Unsicherheit bezüglich der bakteriellen Erreger bzw. Koerreger besteht.
Welche Erreger im Einzelfall gute Kandidaten für eine Koinfektion sind, hängt vom Alter des Patienten, der epidemiologischen Situation und den Durchimpfungsraten bezüglich verfügbarer Impfstoffe ab. Um zumindest klinisch einen Hinweis auf eine bakterielle Koinfektion zu bekommen, werden im klinischen Alltag mehrere Surrogatmarker, wie z. B. das C-reaktive Protein (CRP), die Leukozytenzahl, die Fraktion unreifer Granulozyten und die Blutkörperchensenkungsgeschwindigkeit untersucht. Diese sind jedoch in ihrem Vorhersagewert nicht unumstritten [13].

\section{Diagnostik}

Wie oben gezeigt, ist das Spektrum der Erreger von ARI sehr weit. Die diagnostischen Bemühungen sollten deshalb mehrere Erreger simultan erfassen. Nur bei ei- ner geplanten Intervention gegen einen bestimmten Erreger sind Einzelverfahren sinnvoll. Für systematische Untersuchungen sind sie aber unzureichend, denn Interaktionen mit anderen Erregern können nicht abgeschätzt werden.

\section{„Das Spektrum der Erreger akuter Atemwegsinfektionen ist groß."}

Deshalb haben wir uns für Multiplexansätze entschieden [14,15]. Als Ausgangsmaterial dient das Nasopharyngealsekret (NPS). Das NPS ist die geeignetste Probenart für den Nachweis von viralen Atemwegserregern. Entsprechend dem oben Gesagten sollten nur Erreger in die Methode eingeschlossen werden, die die oberen Atemwege nicht kolonisieren bzw. dort persistieren. Deshalb bleiben 


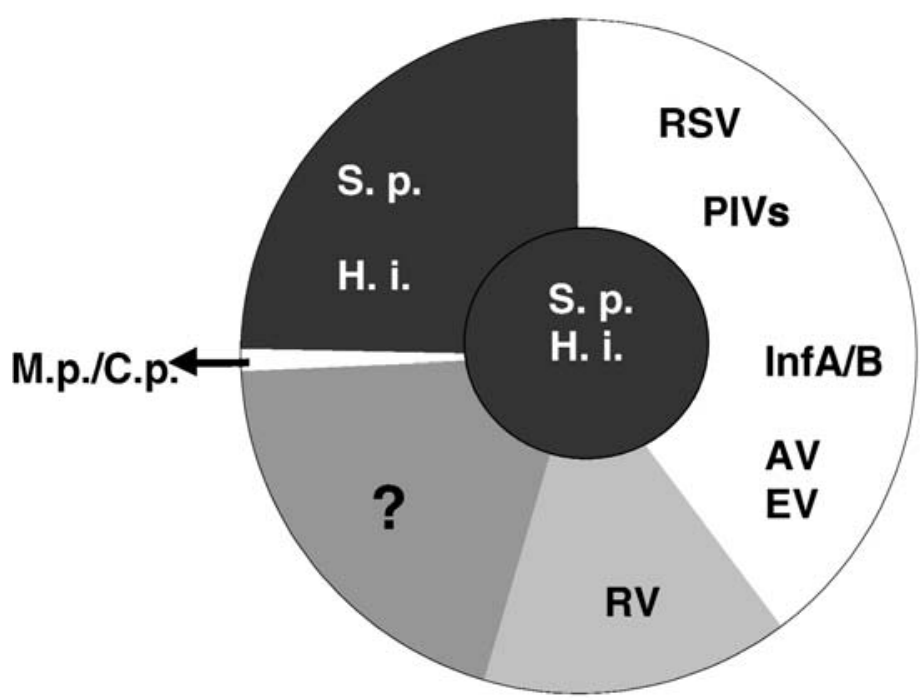

- Streptococcus pneumoniae (S.p.) Haemophilus influenzae (H.i.) u.a. Bakterien (siehe Tabelle 1)

\section{Mycoplasma pneumoniae (M.p.) Chlamydia pneumoniae (C.p.)}

Abb. $2 \triangle$ Erregerverteilung bei tiefen Atemwegsinfektionen (LRI) bei Kindern unter 5 Jahren. Zusammenstellung nach Literatur und eigenen Daten (J.Weigl). RSV respiratorisches Syncytialvirus, PIVs Parainfluenzaviren, InfA/B Influenzavirus A/B, AV Adenoviren, EV Enteroviren, RV Rhinoviren

auch hier die bakteriellen Erreger eine nicht erfasste Größe.

Prinzipiell kommen direkte und indirekte (serologische) Nachweisverfahren in Frage. Für die Akutdiagnostik ist aber immer ein Direktnachweis vorzuziehen (Tabelle 2). Die Serologie kann mittels IgM oder Titerbewegungen von IgG in gepaarten Serumproben einen Nachweis erbringen, ist aber im ersten Fall nicht immer spezifisch und im zweiten Fall zeitraubend, so dass die Antikörperbestimmung ihre Domäne vor allem in der Seroepidemiologie hat. Zum direkten Erregernachweis kommen Immunfluoreszenz, Antigen-ELISA, Viruskultur und molekularbiologische Verfahren in Betracht. Die alleinige Durchführung einer direkten Immunfluoreszenz mithilfe von monoklonalen Antikörpern hat sich nur für RSV in einigen Zentren durchgesetzt. Ansonsten wird sie heutzutage nur in Synopsis mit dem Ergebnis der Viruskultur, oder zum frühen Nachweis einer Virusvermehrung in der Zellkultur verwendet.

Für die meisten Atemwegsviren gilt die Zellkultur als Goldstandard. Mehrere Zelllinien (A549, MDCK, PMK, HEL, Hep2, LLC-MK2 u.a.) kommen zur Anwendung. Falls sie parallel mit einer Probe beimpft werden, haben Zellkulturen aufgrund überlappender Suszeptibilität für verschiedene Viren den Vorteil eines "Screening-Effektes“. Ein genereller Nachteil ist, dass zum Nachweis in Zellkulturen vermehrungsfähige Viren erfor- derlich sind. Dies bedingt einen besonderen Aufwand im Hinblick auf Transportmedien und Logistik. Die Kultivierungszeit konnte in den letzten Jahren für viele Erreger deutlich reduziert werden. Ungeeignet für eine zeitnahe Diagnose ist die Zellkultur für Rhinoviren und vermutlich auch für das neu entdeckte humane Metapneumovirus (hMPV).

\section{Molekularbiologische Verfahren}

NASBA (nucleic acid sequence based amplification) ist eine isotherme Amplifikationstechnik vor allem für RNA-Zielsequenzen. Die LCR (ligase chain reaction) kommt nur bei M. tuberculosis und C. trachomatis zur Anwendung. Am häufigsten wird die PCR (polymerase chain reaction) verwendet. Wird eine reverse Transkription von RNA vorweg durchgeführt, kann das Verfahren für RNA- und DNA-Zielsequenzen verwendet werden. Schnelle Verfahren mit einer Online-Detektion, wie sie z. B. mit dem Lightcycler, dem TaqMan oder dem iCycler durchgeführt werden können, erlauben einen Erregernachweis innerhalb weniger Stunden. Nachteil dieser Techniken ist, dass der simultane Nachweis einer größeren Anzahl von Erregern derzeit noch nicht möglich ist. Für limitierte Untersuchungen, bei denen es um die Geschwindigkeit geht, sind diese Verfahren zwar überlegen, aber Instrumentarium und Reagenzien bisher jedoch sehr teuer.
Für systematische Untersuchungen bezüglich eines größeren Erregerspektrums werden im Projekt PID-ARI.Net Multiplex-PCR-Ansätze favorisiert [14, 15]. Diese erlauben zu kostengünstigen Bedingungen derzeit in einem Ansatz die Erfassung von bis zu 16 Erreger (Entwicklung im Labor Kiel). Dem Problem des ARI-Eisberges, auch in Bezug auf die gewichtete Vielzahl an Erregern, tragen Multiplexansätze am besten Rechnung. Der generelle Vorteil bei diesen Verfahren ist, dass sie kein vermehrungsfähiges Virus sondern nur Nukleinsäuren benötigen. Der entscheidende Nachteil aber ist, dass es aufgrund des Auftretens neuer Mutanten oder der genetischen Variabilität der Atemwegsviren, nicht nur der Influenzaviren, zu so genannten diagnostischen Escapemutanten kommen kann. Mutationen in den Primerbindungsorten oder der Bindungsstelle der Detektionssonde sind meist die Ursache $[5,15]$.

ELISAs kommen vor allem in Form des Antigen-ELISA und in Schnelltesten zur Anwendung. Für RSV, Influenza A und B sind mehrere Teste auf dem Markt. Ihre Sensitivität und Spezifität ist im Vergleich zu den molekularvirologischen Verfahren deutlich schlechter (Sensitivität ca. 40-60\%, Spezifität 80\% [16]), so dass sie für eine Diagnostik auBerhalb der jährlichen Epidemie untauglich sind. Befunde in der Übergangsphase zur Epidemie sollten in jedem Fall durch ein zweites, unabhängiges Verfahren überprüft werden, bis fest- 
Tabelle 2

Übersicht viraler Atemwegserreger (v.a. deutsche Daten)

\begin{tabular}{|c|c|c|c|c|c|c|c|c|}
\hline Erreger & RSV & PIV & Influenza A & Influenza B & Rhinoviren & Enteroviren & Adenoviren & hMPV \\
\hline Zeit & $\begin{array}{l}\text { Jährlich } \\
\text { Frühe Saison } \\
\text { (Sep/Okt.) im } \\
\text { Wechsel mit } \\
\text { später Saison } \\
\text { (Dez/Jan) } \\
\text { Dauer } \\
\text { 4-6 Monate }\end{array}$ & $\begin{array}{l}\text { PIV1/2 } \\
\text { Zweijährig } \\
\text { PIV3 } \\
\text { jährlich } \\
\text { PIV4 } \\
\text { keine Daten }\end{array}$ & $\begin{array}{l}\text { Jährlich } \\
\text { Beginn } \\
\text { Konstant } \\
\text { Dez/Jan } \\
\text { Dauer } \\
\text { 3-4 Monate }\end{array}$ & $\begin{array}{l}\text { 2-4 jährlich } \\
\text { Beginn } \\
\text { Konstant } \\
\text { Dez/Jan } \\
\text { Dauer } \\
\text { 3-4 Monate }\end{array}$ & $\begin{array}{l}\text { Jährlich } \\
\text { 2- bis 3-jährlich } \\
\text { stärkere } \\
\text { Epidemien } \\
\text { Keine Daten aus } \\
\text { Deutschland } \\
\text { Ganzjährig }\end{array}$ & $\begin{array}{l}\text { Jährlich } \\
\text { v.a. } \\
\text { Spätsommer/ } \\
\text { Herbst }\end{array}$ & Ganzjährig & $?$ \\
\hline Person & $\begin{array}{l}\text { Kinder <5 J. } \\
\text { v. a. <2 J. }\end{array}$ & Kinder $<5$ J. & $\begin{array}{l}\text { Alle Altersgrup- } \\
\text { pen v. a. }<5 \mathrm{~J} \text {. }\end{array}$ & $\begin{array}{l}\text { Alle Alters- } \\
\text { gruppen }\end{array}$ & $\begin{array}{l}\text { Alle Altersgrup- } \\
\text { pen v. a. }<5 \mathrm{~J} \text {. }\end{array}$ & $\begin{array}{l}\text { Alle Altersgrup- } \\
\text { pen v. a. }<5 \mathrm{~J} \text {. }\end{array}$ & $\begin{array}{l}\text { Alle Altersgrup- } \\
\text { pen v.a. }<2 \text { J. }\end{array}$ & $\begin{array}{l}\text { Alle Altersgrup- } \\
\text { pen v. a. }<5 \mathrm{~J} \text {. }\end{array}$ \\
\hline $\begin{array}{l}\text { Risiko- } \\
\text { faktoren }\end{array}$ & $\begin{array}{l}\text { Frühgeburt } \\
\text { BPD } \\
\text { Herzkrankheit } \\
\text { Asthma }\end{array}$ & $\begin{array}{l}\text { Vermutlich } \\
\text { wie bei RSV }\end{array}$ & $\begin{array}{l}\text { Frühgeburt } \\
\text { Asthma } \\
\text { Herz }\end{array}$ & $\begin{array}{l}\text { Grundkrank- } \\
\text { heiten } \\
\text { überhaupt }\end{array}$ & $\begin{array}{l}\text { Asthma } \\
\text { Allergiker } \\
\text { BPD, CF }\end{array}$ & & & \\
\hline $\begin{array}{l}\text { Oberflächen- } \\
\text { antigene }\end{array}$ & F-, G-Protein & F-, HN-Protein & $\mathrm{NA}, \mathrm{HA}$ & $\mathrm{NA}, \mathrm{HA}$ & VP1,VP2,VP3 & & & F-, G-Protein \\
\hline $\begin{array}{l}\text { Diagnostischer } \\
\text { Goldstandard }\end{array}$ & $\begin{array}{l}\text { Immunfluores- } \\
\text { zenz, Kultur,PCR }\end{array}$ & Kultur, PCR & Kultur, PCR & Kultur, PCR & PCR & Kultur, PCR & PCR & Kultur, PCR \\
\hline Besonderheiten & $\begin{array}{l}\text { Simultan } \\
\text { mehrere mole- } \\
\text { kulare Cluster }\end{array}$ & & $\begin{array}{l}\text { Segmentiertes } \\
\text { Genom } \\
\text { Ag-shift } \\
\text { möglich }\end{array}$ & $\begin{array}{l}\text { Segmentiertes } \\
\text { Genom } \\
\text { aber nur } \\
\text { Ag-drift }\end{array}$ & >100 Typen & $\begin{array}{l}68 \text { Typen } \\
\text { (außer Polio und } \\
\text { Hepatitis A) }\end{array}$ & $\begin{array}{l}42 \text { Typen } \\
\text { lange Persistenz } \\
\text { in Tonsillen }\end{array}$ & $\begin{array}{l}2 \text { Serotypen } \\
\text { Bedeutung } \\
\text { noch unklar }\end{array}$ \\
\hline
\end{tabular}

BPD bronchopulmonale Dysplasie; CF cystische Fibrose, PCR Polymerasekettenreaktion, RSV Respiratory Syncytial-Virus, PIV Parainfluenzavirus, hMPV humanes Metapneumovirus.

steht, dass die Epidemie tatsächlich begonnen hat. Ein akkurates Testverfahren ist insbesondere auch für Entscheidungen zur Durchführung einer riskanten Therapie vonnöten.

\section{Individuelle und epidemiologi- sche Pathogenitätsfaktoren}

ARI sind bei Kindern aus individuellen, altersabhängigen und epidemiologischen Gründen von großer Bedeutung:

Individuelle und altersabhängige Faktoren

D Eine spezifische Immunität gegenüber der Vielzahl der Erreger wird erst mit zunehmenden Alter aufgebaut.

D Die Leihimmunität der Mutter ist von ihrer Exposition abhängig, unvollständig, nicht für alle Erreger gleich schützend und verliert sich mit zeitlichem Abstand von der Geburt.
Das Immunsystem ist noch unreif, insbesondere das B-Zellsystem (Isotypwechsel, Affinitätsreifung). So können Kinder unter 2 Jahren noch keine ausreichende IgG-Antwort gegenüber bekapselten Bakterien entwickeln.

D Die Muttermilch enthält protektive Faktoren (Nichtstillen als Risikofaktor), die wahrscheinlich die Bindung von ARI-Erregern an Rezeptoren unterbinden.

D Epidemiologisch erkannte Risikofaktoren sind z. B. soziale Faktoren, Mangelernährung und männliches Geschlecht (Relatives Risiko 1,3).

- Der anatomische Durchmesser der Atemwege steigt mit zunehmendem Alter an. Der Radius beeinflusst den Luftstrom mit der 4. Potenz, so dass die Gefährdung durch eine ARI rasch zunehmen kann, je jünger das Kind ist.

- ARI beim Vorliegen einer Grundkrankheit (Herzfehler, Asthma, bronchopulmonale Dysplasie (BPD), neu- rologisches Leiden) gefährden den Patienten besonders.

Epidemiologische Faktoren

- Die Expositionen im Haushalt (Familiengröße als Variable) oder bei Besuch von Gemeinschaftseinrichtungen (crowding), wie z. B. dem Kindergarten oder Kindertagesstätten ist altersspezifisch. Kinder werden im Durchschnitt monatlich mit einem neuen Pneumokokkenstamm konfrontiert [17].

Der Jahreszyklus mit Schul- und Kindergartenferien hat erhebliche Auswirkungen auf die Ausbreitung von ARI-Viren.

D Die sozialen Kontakte der Kinder untereinander sind enger als im Erwachsenenalter.

D Bei schlechterer Witterung, wie im Winter, rücken die Menschen näher zusammen, und eine Übertragung wird leichter möglich (CrowdingEffekt). 


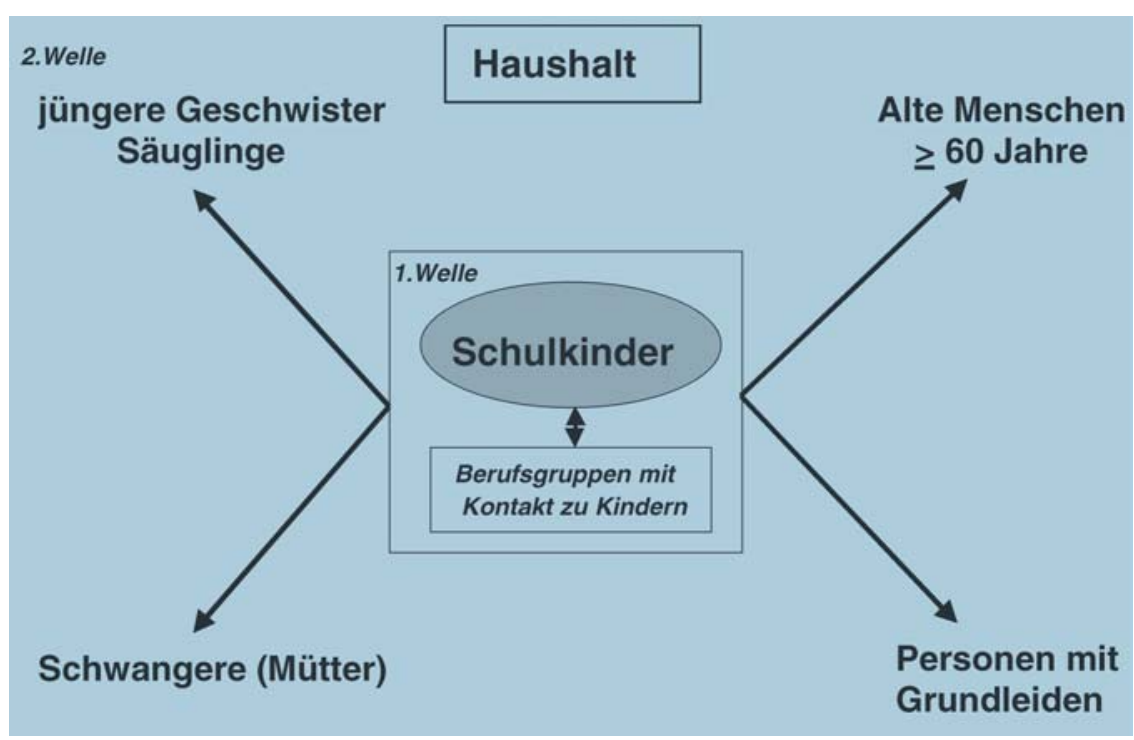

Abb. $3 \Delta$ Schulkinder als „,Turbomechanismus“ für die Ausbreitung von tiefen Atemwegsinfektionen (ARI)

D Eine Erhöhung der Luftfeuchtigkeit und ein Absinken der Außentemperatur im Winter begünstigt das Überleben von freigesetzten Viren.

De länger die Verweildauer in medizinischen Einrichtungen beim Vorliegen einer Grundkrankheit ist, um so leichter kommt es zu einer nosokomialen Infektion.

D Die Virusausscheidung von Kindern dauert im Allgemeinen länger als bei Erwachsenen, insbesondere bei Frühgeborenen kann sie mehrere Monate betragen.

D Je ausgeprägter die Genomvariabilität eines Virus, d. h. je größer die Zahl seiner Varianten, desto eher kommt dieses Virus auch bei älteren Kindern und Erwachsenen vor („Subtypenphänomen“ [18], immunologisches „escape“).

D Asymptomatische Erwachsene stellen den größten Teil des Reservoirs dar.

Kindergarten- und Schulkinder (Abb.3) sind selbst im Falle einer nur geringfügigen Krankheitssymptomatik für die Übertragung von Atemwegsinfektionen und für die Ausbreitungsdynamik von entsprechenden Epidemien als Multiplikatoren von zentraler Bedeutung [19, 20, 21, 22]. Nach einer 1. Erkrankungswelle im Klassenverband oder in der Spielgruppe kommt es zu einer 2. Erkrankungswelle in den Haushalten/Familien. Dort werden die Infektionen auf vulne- rable Familienmitglieder oder Bevölkerungsteile übertragen.

\section{Atemwegsviren im Einzelnen} oder Grundgröße für die Beobachtung des Auftretens von ARI schlecht, denn ARI treten insbesondere im Winter auf, so dass das Kalenderjahr eine Epidemie teilen würde. Geeigneter ist das so genannte „epidemiologische Jahr“. Es reicht von Juli des einen Jahres bis Ende Juni des folgenden Jahres und schließt die Wintersaison vollständig ein. Die Inkubationszeit wird in der Literatur unterschiedlich angegeben und kann für alle Atemwegsviren 1 bis 10 Tage (für Influenza 1-5 Tage) betragen [23]. Die Erreger treten $\mathrm{z}$. T. in klar umschriebenen Ausbrüchen mit unter Umständen mehrjährigen Abständen oder ganzjährig (endemisch) mit saisonalen Schwerpunkten auf (Abb. 4, s. Tabelle 2). Die Konkurrenz um den oben erwähnten Turbomechanismus ist dabei vermutlich von entscheidender Bedeutung [22].

\section{Respiratory Syncytial Virus (RSV)}

Das RSV gehört zur Familie der Paramyxoviren, Subfamilie Pneumovirinae, Genus Pneumovirus, hat ein negativ orientiertes (-), einzelsträngiges (ss) RNA-Genom mit 10 offenen Leserahmen (ORF). Die Oberflächenproteine $\mathrm{F}$ und $\mathrm{G}$ sind von zentraler Bedeutung. Es wird ein
Das Kalenderjahr eignet sich als Einheit
Typ A und ein Typ B unterschieden. Darüber hinaus lassen sich auch in Deutschland mehrere molekulare Cluster unterscheiden, deren Prävalenz nach Ort und Zeit variiert (Forster persönl. Mitteilungen). Ihre pathogenetische Bedeutung ist nicht abschließend geklärt.

Zur Epidemiologie der RSV-Infektion bei Kindern in Deutschland, insbesondere zu RSV-positiven Hospitalisationen und damit zur Spitze des Eisberges in Abb. 1, wurden in den letzten Jahren eine Vielzahl an Daten publiziert $[5,6,18,24$, 25, 26, 27, 28]. Nachdem RSV bei Kindern bekanntermaßen das wichtigste Atemwegsvirus darstellt und jüngst eine Prävention möglich wurde, schien diese Prioritätensetzung sinnvoll. Zudem soll RSV als Maßeinheit zur Gewichtung der übrigen Atemwegsviren bei Kindern dienen [6]. Epidemien treten jährlich auf (s. Tabelle 2 und Abb. 4). Von 1994/95 bis 1996/97 traten die jährlichen Ausbrüche spät (Beginn Dez./Jan.) auf. Seit 1997/98 folgt einer späten Saison eine frühe (Beginn Sep./Okt.), so dass sich eine Art „Zweierpack“ ergibt [24]. Über diesen Rhythmus scheint ein weiterer, mehrjähriger (z.B. 4 Jahre) gelagert zu sein (s. Abb. $4)$, denn nach einer schwachen Saison 1997/98 kam es zu einem laufenden Anstieg der Inzidenz RSV-positiver Hospitalisationen, bis 2001/2002 ein Jahr mit einer wiederum geringen Inzidenz folgte. Diese Aussagen müssen aber noch durch weitere longitudinale Daten erhärtet werden. Dieser duale Rhythmus entspricht dem in anderen Ländern, wie z.B.in Finnland über 10 Jahre beschriebenen [29].

\section{„Bis zum 2. Lebensjahr haben alle Kinder eine RSV-Infektion durchgemacht."}

Gemessen an den Antikörpertitern haben bis zum 2. Geburtstag alle Kinder ihre erste Infektion mit dem Virus durchgemacht [30]. Die Inzidenz RSV-positiver Hospitalisationen liegt im Raum Kiel für das erste Lebensjahr bei 1214/10 (1,2\% oder 1 von 82 Säuglingen) und für das 2. Lebensjahr bei $725 / 10^{5}(0,7 \%)$ und entspricht damit der Inzidenz in unseren Nachbarländern [5]. Bei Frühgeborenen (FG) der 32. bis 36. Schwangerschaftswoche (SSW) liegt die Inzidenz 2 mal, für FG unter der 32. SSW 3 mal höher als bei reifen Kindern (dose-response effect). Bei FG unter der 32. SSW mit zusätzlich 
einer bronchopulmonalen Dysplasie (BPD) als Grundkrankheit erhöht sich das relative Risiko (RR) um das 17 -fache im Vergleich zu FG unter der 32. SSW ohne BPD. Kinder mit einem Herzleiden haben ein RR von 8,5 und Kinder mit Asthma ein RR von 2,1 [6].

Kinder werden überwiegend wegen einer Pneumonie (54\%) oder einer obstruktiven Bronchitis/Bronchiolitis (27\%) hospitalisiert. Bei Kindern unter 2 Jahren kann unter Berücksichtigung des Alters (je jünger), der Entität (Pneumonie oder obstruktive Bronchitis), der Präsenz von interkostalen Einziehungen, dem nicht Vorliegen einer Grundkrankheit, niedriges CRP, kurze Vorgeschichte und Frühgeburtlichkeit nur mit einer Sensitivität von $72,8 \%$ und einer Spezifität von $74,9 \%$ klinisch auf eine RSVÄtiologie geschlossen werden. Bei einer maximalen RSV-Punktprävalenz von $20 \%$ bei saisonalen ARI-Hospitalisationen wird deshalb maximal ein positiver Vorhersagewert (PPV) von 50\% erreicht. Deshalb ist für weitergehende Maßnahmen eine Erreger-spezifische Diagnose indiziert [26]. Auch eine Röntgendiagnostik erhöht die klinische Vorhersagbarkeit nicht $[26,27]$.

Die Dauer der Hospitalisation beträgt, wie in anderen kontinentaleuropäischen Ländern, im Durchschnitt 9 Tage $[25,26,27,31]$. Sie verkürzt sich jedoch allmählich [26]. Sie wird bestimmt durch das Alter des Patienten, das Vorliegen einer Grundkrankheit, die Krankheitsentität und -schwere (Präsenz von interkostalen Einziehungen bei Aufnahme). Der Erreger selbst hat keinen direkten Einfluss, sondern nur einen indirekten über die Altersprädilektion [26]. Nachdem das Problem einer bakteriellen Koinfektion, wie oben dargelegt, nur angenähert werden kann, kann anhand altersentsprechender CRP-Grenzwerte und der Fraktion unreifer Granulozyten in $20-30 \%$ von einer solchen ausgegangen werden [25].

\section{Parainfluenza (Typ 1, 2, 3, 4)}

Parainfluenzaviren (PIV) sind (-) ssRNAViren der Familie Paramyxoviren, Subfamilie Paramyxovirinae. PIV1 und 3 gehören zum Genus Respirovirus, PIV 2 und 4 zum Genus Rubulavirus (s. Tabelle 2).

PIV1 tritt regelmäßig nur alle $2 \mathrm{Jah}$ re vor allem im September und Oktober auf (s. Abb. 4, [32]). In Deutschland wa-
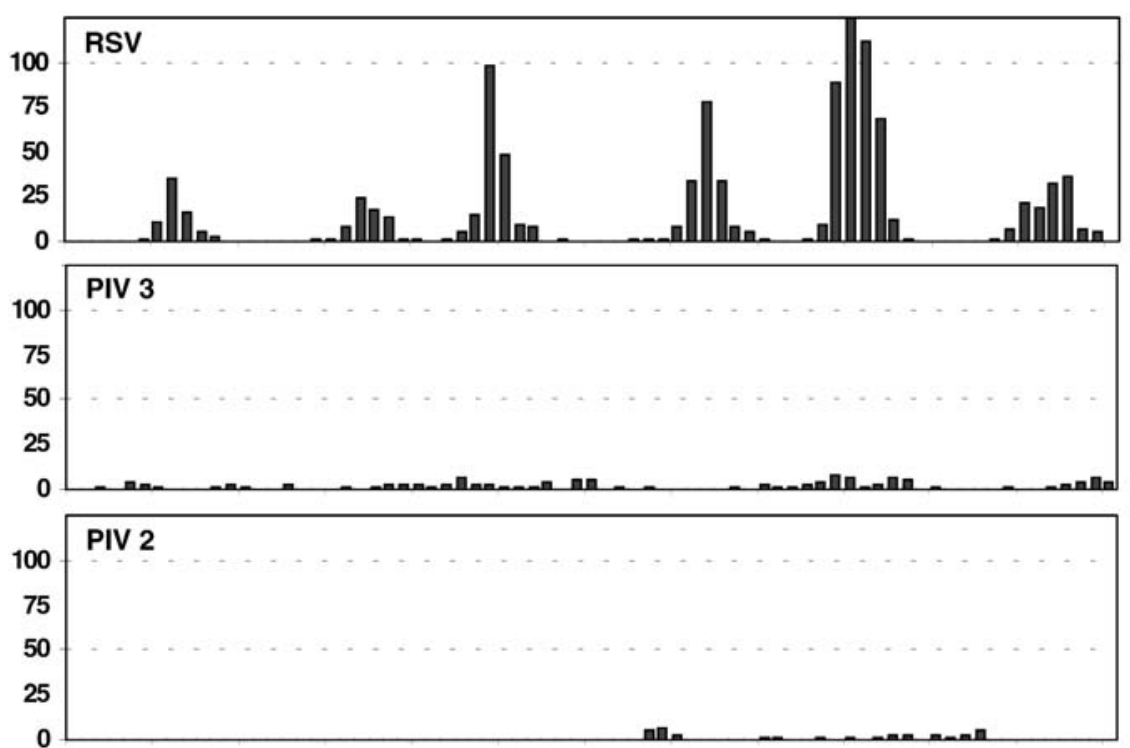

100

PIV 1

75

50

25

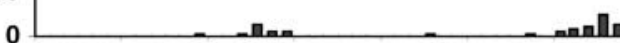
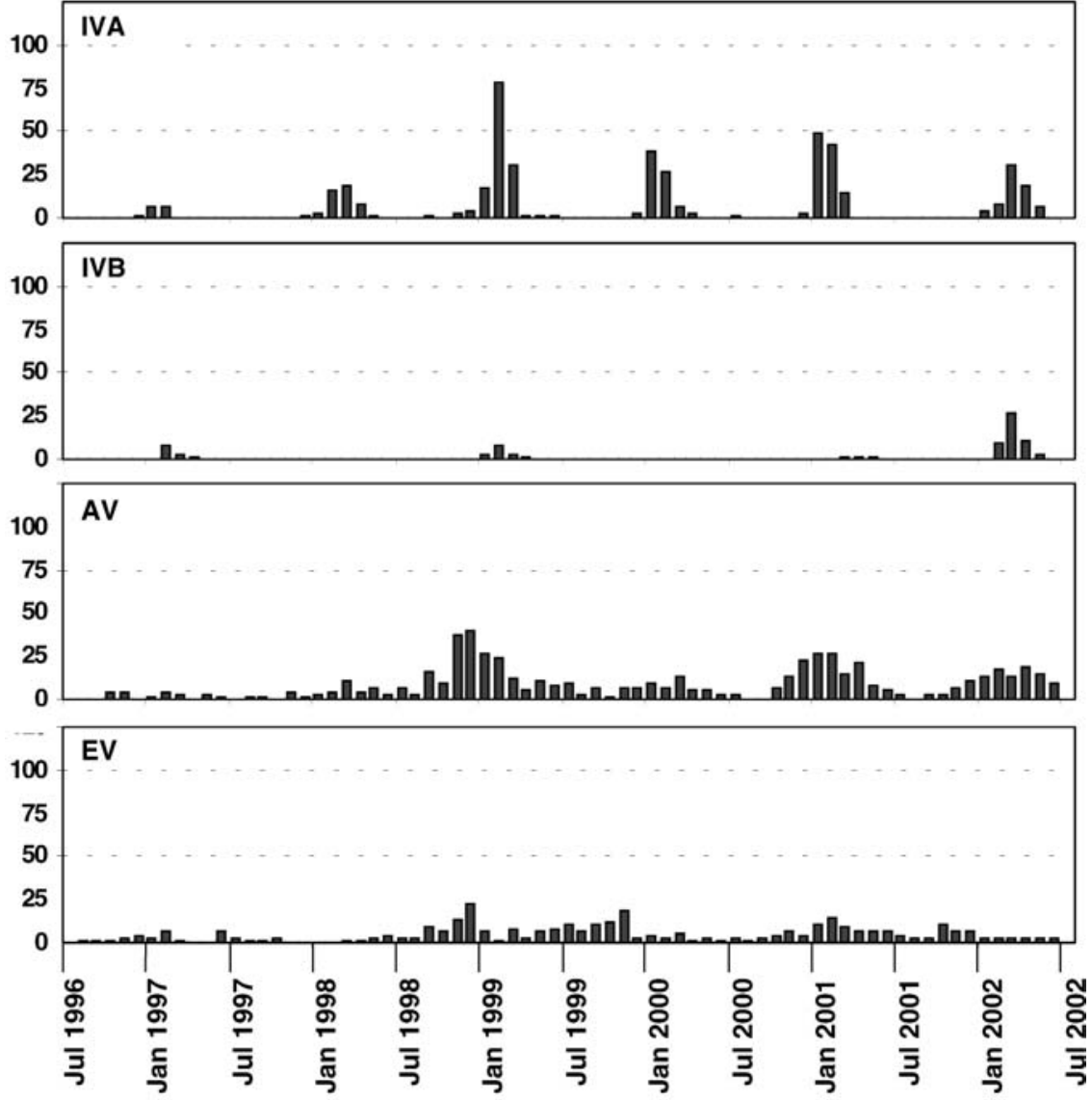

Abb.4 $\triangle$ Saisonalität viraler Atemwegserreger in Deutschland 1996-2002. Absolute Zahl positiver Befunde Kiel, Daten für PIV2 aus PRI.DE (1999-2001). RSV Respiratory Syncitical-Virus, IVA Influenzavirus A, IVB Influenzavirus B, AV Adenoviren, EV Enteroviren, PIV2 Parainfluenzavirus 2 
ren dies zuletzt die epidemiologischen Jahre 1997/98, 1999/oo und 2001/02. PIV1 scheint mit dem Epidemiebeginn von RSV zu interagieren und die RSV-Saison spät beginnen zu lassen (s. Abb. 4, [33]). Vor allem Kinder unter 5 Jahren werden mit PIV1 hospitalisiert. Das gesamte Spektrum an LRI, v.a. aber auch LTB (Laryngotracheobronchitis), kommt vor [18]. Der Anteil am ARI-Eisberg beträgt ca. $1 / 10$ von RSV.

Die Saisonalität von PIV 2 entspricht jener von PIV1, aber der Anteil am ARIEisberg ist geringer [32,33]. Die Daten aus PRI.DE (s. Abb. 4) ergeben neben den 2 Häufungen im Herbst 1999 und Frühherbst 2001 auch einzelne Fälle (in den Praxen) über das ganze Jahr, jedoch ohne hospitalisationspflichtige Erkrankungen.

$\mathrm{PIV}_{3}$ tritt ganzjährig mit jahreszeitlichen Schwerpunkten auf (s. Abb. 4, [32, 33]. Im Rahmen der genetischen Variabilität traten mehrere Mutationen in den Primerbindungsbereichen des 5'-nichtkodierenden Teils des Fusionsproteins, der von Karron et al. [34] beschriebenen PCR, auf. Da diese Primer auch in der 9valenten Multiplex-RT-PCR [14] in Kiel benutzt wurden, wurde die Inzidenz von PIV3 um ca. 30\% unterschätzt. Der Wechsel zu Primern für das Haemagglutiningen [35] behob das Problem. Die Bedeutung von $\mathrm{PIV}_{3}$ entspricht ca. 1/5 derjenigen von RSV, muss jedoch mit Daten der neuen PCR nochmals bewertet werden. Der Anteil der Krankheitsbilder und die Altersstruktur entspricht der von RSV.Allerdings ist der Anteil von LTB höher [18].

Innerhalb von PIV4 werden die Typen $\mathrm{A}$ und $\mathrm{B}$ unterschieden. $\mathrm{Zu}$ diesem Erreger gibt es nur wenige systematische Daten und keine aus Deutschland. PIV4 wurde vor allem im Patientengut neonataler Intensivstationen beschrieben [36] Der Anteil am ARI-Eisberg erscheint gering [32].

\section{Influenzaviren $(A, B, C)$}

Influenza-A-Virus (IVA), ein (-) ssRNAVirus mit 8 Genomsegmenten, ist eines der potentesten Atemwegsviren. Aufgrund des segmentierten Genoms kann es sich neu kombinieren; vor allem auch mit IVA-Virustypen aus dem Tierreservoir Wildvögel (Antigenshift). Ansonsten ändert sich das Virus fortwährend im Rahmen des Antigendrift. IVA ruft jährlich Epidemien unterschiedlichen Ausmaßes hervor. Sie beginnen meist zwi- schen der 50. und 5. Kalenderwoche und dauern 3-4 Monate an [6, 7]. Epidemiologische Interferenzen mit anderen ARIViren, vor allem mit RSV, sind gut in der Literatur beschrieben [21] und gelten vermutlich auch für Deutschland [6,22]. Die populationsbezogene Inzidenz von IVApositiven Hospitalisationen bei Kindern bis 16 Jahre entspricht ca. einem Drittel der von RSV. Sie ist deutlich verschoben hin $\mathrm{zu}$ älteren Kindern und erreicht bei 2- bis 5-Jährigen (101/105) die von RSV $\left(115 / 10^{5}\right)$ [6]. Die Inzidenz entspricht damit der jüngst aus den USA berichteten [37]. Kinder mit Herzleiden (RR 9,8), Asthma (RR 4,1) und Frühgeborene (RR 2,1) haben ein erhöhtes Risiko, schwer an IVA zu erkranken. Die auf Daten anderer Länder (USA, UK) basierenden Empfehlungen der STIKO zur aktiven Impfung von Kindern sind nun auch mit gut korrelierenden deutschen Daten belegt.

Das Krankheitsspektrum bei IVA ist deutlich weiter als bei RSV. Es kommen neben unteren auch obere Atemwegsinfektionen (einschließlich 30\% der Otitis-media-Fälle) sowie systemische Erkrankungen, wie z. B. Myolyse, Sepsis und Enzephalitis vor. Da aufgrund des limitierten Anteils von Influenza am Gesamt-ARI-Eisberg eine Erfassung von „Influenza-like illness (ILI)“ (eine syndromale Erfassung) für Kinder unbrauchbar ist, ist eine Erreger-spezifische Diagnostik vorzuziehen.

Das Influenza-B-Virus, ebenfalls ein (-) ssRNA-Virus mit 8 Segmenten, ist deutlich weniger virulent als IVA. Es unterliegt nur einem Antigendrift und tritt nur alle 2-4 Jahre in epidemischen Ausmaßen auf.Zuletzt waren das in Deutschland 1996/97,1998/99 und 2001/02. Die Inzidenz IVB-positiver Hospitalisationen beträgt 1/10 derer von RSV und ist noch deutlicher hin zu älteren Kindern verschoben; der Anteil an Kindern mit einer chronischen Grundkrankheit ist hier besonders hoch (43\%) [6].

Das Influenza-C-Virus, ein (-) ssRNA-Virus mit nur 7 Segmenten, ist nur bei lokalen Ausbrüchen insbesondere aber bei Kindern beschrieben worden [38].

\section{Picornaviren (Rhinoviren, Enteroviren)}

Rhinoviren (RV) gehören zu den Picornaviren, $(+)$ ssRNA-Viren mit einem ORF und 3 Oberflächenproteinen $\left(\mathrm{VP}_{1}-3\right)$. Sie treten das ganze Jahr hindurch auf, ge- häuft aber im Herbst und Winter. Da das Virus in Zellkultur schwer anzuzüchten ist, ist hier die PCR die Nachweismethode der Wahl. Lange Zeit wurde die Ansicht vertreten, dass RV nur Erkältungen und Infektionen der oberen Luftwege verursachen. In den letzten Jahren wurden jedoch mehrere Untersuchungen bekannt, die RV als Ursache von LRI nahe legen [39, 40, 41, 42]. Ruuskanen [43] berichtete bisher den höchsten Anteil von 24\% von RV an ambulant erworbener Pneumonie bei Kindern. Da RV aber relativ lange vom Wirt ausgeschieden werden können und wegen des oben geschilderten diagnostischen Dilemmas, sind diese Daten aber nicht unumstritten. Kinder mit Asthma, Allergien, BPD und zystischer Fibrose haben ein erhöhtes Erkrankungsrisiko. Systematische Untersuchungen, vergleichend mit anderen ARI-Viren, fehlen bislang, insbesondere auch für Deutschland. Wenn auch noch kontrovers diskutiert, ist anzunehmen, dass durch RV das volle LRI-Krankheitsspektrum hervorgerufen werden kann. LRI in epidemischen Ausmaßen scheinen aber trotz der Vielzahl der RV-Typen mehrjährige Abstände zu haben (persönliche Beobachtungen aus Dallas). Aufgrund der Vielzahl an Virustypen (>100) kann ein Mensch mehrfach in einer Saison eine RV-Infektion durchmachen, laut Literatur 1,5 bis 2,9 Infektionen pro Jahr [44]. Mehrere Wellen unterschiedlicher Typen können eng aufeinander folgen. Die Epidemiologie wird entscheidend von den oben beschriebenen Mechanismen (Turbomechanismus) und „crowding“ bestimmt. Wegen der hohen Inzidenz, auch in tiefer gelegenen Segmenten des ARIEisberges (s. Abb. 1), besteht großes Interesse an Interventionsmöglichkeiten (Inhibitoren oder Impfstoffen).

Es gibt insgesamt 72 humanpathogene Enteroviren (EV), von denen einige gesichert ARI hervorrufen können. Da das Genom große Homologien zu RV aufweist, können PCRs oft nicht sicher zwischen beiden unterscheiden. Jedoch können die von Rotbart et al. [45] beschriebenen EV-Primer gut zwischen RV und EV diskriminieren, so dass die Kieler Daten spezifisch für EV sind [14, 15, 18]. Da EV mehrere Wochen im Wirt persistieren können und der klinische Verlauf asymptomatisch sein kann, sind EV gute Kandidaten für Doppel- oder Mehrfachinfektionen. Dies erschwert die Abschätzung ihres Anteils am ARI-Eis- 
berg. EV-assoziierte ARI treten ganzjährig aber mit einem Schwerpunkt im Spätsommer und Herbst auf. Der Anteil an ARI-hospitalisierten Kindern betrug $4 \%$ oder ca. $30 \%$ des RSV-Anteils. Es erkranken vor allem Kinder unter 5 Jahren, die das gesamte LRI-Krankheitsspektrum zeigen können.

\section{Adenoviren (AV)}

AV sind Doppelstrang-DNA-Viren mit 42 Typen beim Menschen. Typ 1-5, 7, 14 und 21 werden in der Regel bei ARI gefunden [46]. Gegen Typ 4 und 7 werden in der US-Armee Vakzinen eingesetzt. AV-assoziierte ARI haben einen Häufigkeitsgipfel im Winter, kommen aber ganzjährig vor (s. Abb. 4). Da AV als DNA-Viren sehr stabil sind, über mehrere Monate nach durchgemachter Infektion aus den Tonsillen ausgeschieden werden können und viele PCR-Verfahren sehr sensitiv sind, wird der Anteil von AV am ARI-Eisberg sicherlich überschätzt ( $8 \%$ an allen ARIHospitalisationen, $60 \%$ des Anteils von RSV). Aus den genannten Gründen sind $\mathrm{AV}$ auch die Hauptkandidaten für Doppel- und Mehrfachinfektionen. Insbesondere bei Kindern unter 2 Jahren und Immunsupprimierten wurden sehr schwere Verläufe beschrieben.

\section{Humanes Metapneumovirus (hMPV)}

Das hMPV gehört zur Familie der Paramyxoviren, Subfamilie Pneumovirnae, Genus Metapneumovirus und wurde 2001 erstmals beschrieben [47]. Das Virus ist eng verwandt mit den Pneumonieviren der Vögel (APVc). Laut vorläufigen Daten aus den Niederlanden kann das Virus alle Altersgruppen betreffen, vor allem aber Kinder unter 5 Jahren. Es zirkuliert mindestens schon seit 50 Jahren. Das Krankheitsspektrum scheint dem von RSV sehr ähnlich zu sein. Die Rhythmizität des Virus und Risikofaktoren sind noch unklar. Wie groß der Anteil am ARIEisberg tatsächlich ist, ist momentan noch nicht sicher und vermutlich bisher überschätzt [48]. Der Anteil an konventionell negativ getesteten NPS-Proben beträgt $2-10 \%$. Für Deutschland sind erst Ende des Jahres 2003 Daten zu erwarten. Wegen der langen Bebrütungszeit in Zellkultur (>14 Tage) werden sich wahrscheinlich PCR-Verfahren als diagnostischer Goldstandard für die akute Diagnostik durchsetzten.

\section{Andere Viren}

Von der Vielzahl von Coronaviren spielen nur Typ OC43 und 229 E eine Rolle. Ihr Anteil am ARI-Eisberg ist marginal (Institut für Virologie Universität Rotterdam persönliche Mitteilung).

Nachdem die Durchimpfungsraten für Masern zwischen 80 und $85 \%$ liegen, kommen sie heutzutage nennenswert nur noch in lokalen Ausbrüchen vor, wie sie mehrfach im Epidemiologischen Bulletin des Robert Koch-Instituts beschrieben wurden. Bei zunehmender Durchimpfungsrate werden sich die Abstände dieser Ausbrüche vergrößern. Modelling wird dann verwendet, um landesweite Ausbrüche vorherzusagen, wie bereits in England und Portugal geschehen. Aufgrund des hohen Reproduktionskoeffizienten von Masern sowie der notwendigen Durchimpfungsrate von ca. $97 \%$ ist eine Eradikation von Masern in Deutschland wenig aussichtsreich.

ARI durch Herpesviren, v.a. durch das Cytomegalievirus (CMV), betreffen hauptsächlich Kinder unter immunsuppressiver Therapie. In der normalen pädiatrischen Population ist bei einer Durchseuchung mit CMV von $1 \%$ bereits bei Geburt und einer lebenslangen Persistenz des Virus ein kausaler $\mathrm{Zu}$ sammenhang ohne invasive Methoden selten herzustellen. Varizella-Zoster-Virus-(VZV) Pneumonien spielen bei Erstinfektionen im Adoleszenten- oder Erwachsenenalter, insbesondere aber bei immunsupprimierten Patienten, eine Rolle.

\section{Nosokomiale Infektionen}

Nosokomiale Infektionen und Ausbrüche wurden für die meisten Atemwegsviren beschrieben. Bei Influenza-positiven, hospitalisierten Patienten betrug der Anteil nosokomialer Infektionen 9\% [6]. Die detailliertesten Daten zu nosokomialen Infektionen in Deutschland gibt es für RSV. Grundsätzlich sollten diese Erkenntnisse auf andere ARI-Viren übertragbar sein. Relevant sind nosokomiale RSV-Infektionen auf neonatologischen Stationen, insbesondere Intensivstationen. Bereits 1979 wiesen Hall et al. darauf hin, dass 35\% aller RSV-Infektionen auf neonatologischen Intensivstationen nosokomialen Ursprungs sein können [49]. In einer retrospektiven Analyse an der Universitätskinder- klinik Freiburg wurden in einer hospitalbasierten Studie 1.171 RSV-Krankheitsepisoden zwischen 1988 und 1997 analysiert. Die Rate nosokomialer Infektionen betrug hier 38\% [27]. In einer 2. Analyse von April 1997 bis März 1999 wurden $32 \%$ der Patienten als nosokomial infiziert eingestuft, $2 / 3$ davon waren Frühgeburten (FG). Entsprechend der Hospitalisierungsdauer betrug die nosokomiale Infektionsrate bei FG unter 28 Wochen $47 \%$, bei FG 28 bis 32 Wochen $18 \%$, und bei FG 33 bis 37 Wochen $4 \%$. Die Letalität in diesen Studien lag bei etwa $0,7 \%$ und betraf ausschließlich Kinder mit BPD und nosokomial erworbener Infektion [27].

\section{"Nosokomiale RSV-Infektionen sind insbesondere auf neona- tologischen Intensivstationen ein Problem."}

Schmierinfektionen spielen nachgewiesenermaßen bei nosokomialen Infektionsketten die wesentliche Rolle. RSV bleibt für 6 Stunden und länger auf Oberflächen - unter anderem für bis $\mathrm{zu} 24$ Stunden auf Stethoskopmembranen und etwa 30 Minuten z. B. auf Taschentüchern kontagiös. Eintrittspforten sind überwiegend die Konjunktiven und die Nasenschleimhäute. Medizinisches Personal spielt während der RSV-Saison eine entscheidende Rolle in der Transmission des Virus, wahrscheinlich insbesondere durch die unbewusste Berührung der eigenen Schleimhäute, nicht zuletzt der Konjunktiven [50]. Die Rate an nosokomialen RSV-Infektionen schwankt sehr stark zwischen unterschiedlichen Institutionen, was direkt von räumlichen und baulichen Gegebenheiten und der Möglichkeit der Isolierung oder Kohortenisolierung abhängt $[51,52]$. In mehreren Studien konnte nachgewiesen werden, dass die Anzahl von infizierten Kindern auf einer neonatologischen Station linear mit der nosokomialen Transmissionswahrscheinlichkeit korreliert [50, 53]. Zur Prävention nosokomialer Infektionen sind neben - nicht immer realisierbaren räumlichen Veränderungen verschiedene Maßnahmen evaluiert und empfohlen. Dazu gehören die Isolierung bzw. Kohortenisolierung infizierter Patienten, die sorgfältige alkoholische Händedesinfektion sowie die intensive Schulung des Personals [54]. 


\section{Prävention und Therapie}

Die Behandlungsmöglichkeiten viraler ARI lässt sich folgendermaßen zusammenfassen: Es sind Virusstatika mit kaum nachweisbarem Nutzen vorhanden (z. B. Ribavirin bei RSV-Infektion), bei anderen ist der Nutzen prinzipiell nachgewiesen, setzt aber eine rasche spezifische Diagnose voraus (Amantadin bei Influenza A). Neuere Therapeutika/Prophylaktika wiederum (Neuraminidasehemmer für Influenza) bedürfen gegenwärtig einer noch breiteren Evaluation im Hinblick auf ihren Einsatz bei Kindern, andererseits sind sie derzeit noch sehr teuer. Die adjuvante medikamentöse Therapie (Beta-Mimetika und Cortison bei RSV) ist generell wenig bis kaum wirksam. Die adjuvante klinische Therapie beinhaltet das eingangs erwähnte Stufenschema [25].

Generell kommt daher der Prophylaxe, gegenwärtig und prospektiv, der höchste Stellenwert zu, d.h:

a) Im Umgang mit hospitalisierten Kindern haben sich neben den üblichen Hygienemaßnahmen, Kohortierungen von Patienten, die an denselben ARI-Erregern erkrankt sind, als sehr wirksam erwiesen. Diese Maßnahmen können aber nur in Kenntnis der Ätiologie erfolgen, ein Ziel, dem sich die Untersuchungen des PID-ARI.Net soweit nähern, wie bislang keine andere Studie.

b) Für ehemalige Frühgeborene mit einem hohen Risiko für weitere Lungenschäden durch RSV steht eine Prophylaxe mit einem RSV-Antikörper (Palivizumab) zur Verfügung [55, 56]. Die Indikationen sind jedoch umstritten. Die Vakzinwirksamkeit für das Vermeiden einer RSV-positiven Hospitalisierung lag bei nur 55\% [57]. Die Kosten können aber durch Epidemie-synchrone Anwendung eingeschränkt werden. Voraussetzung hierfür ist eine sehr zeitnahe Information der Betroffenen und ihrer Ärzte (siehe Web-basiertes Frühwarnsystem).

c) Aktive Impfungen werden letztlich den besten Schutz vor schweren ARI bieten. Dieser Schutz muss jedoch seine Kosten rechtfertigen. Hier bieten die epidemiologischen Daten von PID-ARI.Net den Zugang zu Kosten-Nutzen-Kalkulationen. d) Analog zu den Influenzaviren ist bei allen ARI-Erregern damit zu rechnen, dass Erregerwandel Impfstoffe unwirksam machen könnten. Es wird daher eine langfristige Netzwerkaufgabe bleiben, solche Entwicklungen frühzeitig, beispielsweise mit molekularen Methoden, zu erkennen und entsprechende Handlungsempfehlungen zu geben.

\section{Web-basiertes Frühwarnsystem und PID-ARI.Net}

Aufgrund der großen Bedeutung von ARI bei Kindern, dem bestehenden Bedarf an einer Erreger-spezifischen Surveillance eines möglichst großen Spektrums und der Notwendigkeit die erhobenen Daten unmittelbar an die behandelnde Ärzteschaft weiterzuleiten, haben wir im Forschungsnetzwerk PID-ARI.Net ein sog. Web \& Warnsystem entwickelt. Wir bieten diese Information in wöchentlicher Aktualisierung im Internet unter http:// www.PID-ARI.net an. Hier gehen Daten aus 6 Kliniken und mehreren Praxen im Raum Freiburg, Mainz und Kiel ein. Wie oben ausgeführt, ist im Kindesalter, im Gegensatz zu Erwachsenen, eine syndromale Surveillance von z. B. ILI (influenza like illness), unzureichend. Diese Art epidemiologischer Diagnostik und Hintergrundinformation soll den positiven Vorhersagewert (PPV) in der ärztlichen Praxis steigern, kann aber im Einzelfall die Erreger-spezifische Einzeldiagnose nicht ersetzen. Mit diesem System hoffen wir einen Beitrag zur Verbesserung der Versorgung von pädiatrischen ARI-Patienten leisten zu können und das Bewusstsein für dieses Krankheitsspektrum in Deutschland nachhaltig zu schärfen.

\section{Anmerkungen}

Das Forschungsnetzwerk „PID-ARI.Net“ (pediatric infectious diseases acute respiratory tract infections network) wird im Rahmen des vom BMBF geförderten und von der DLR betreuten Forschungsnetzwerke in Infektionsepidemiologie gefördert. Die Autoren und ihre Institutionen arbeiten darin zusammen.

\section{Literatur}

1. Michaud CM, Murray CJL, Bloom BR (2001) Burden of disease - implications for future research. JAMA 285:534-539

2. Garenne M, Ronsmans C, Campbell H (1992) The magnitude of mortality from acute respiratory infections in children under 5 years in developing countries. World Health Stat Q 45:180-191

3. Leowski J (1986) Mortality from acute respiratory infections in children under 5 years of age.Global estimates. World Health Stat Q 39:138-144

4. Weigl JAI, Bader HM, Everding A, Schmitt HJ (in press) Population-based burden of pneumonia until school entry in Germany. Eur J Pediatr

5. Weigl JAI, Puppe W, Schmitt HJ (2001) Incidence of respiratory syncytial virus-positive hospitalizations in Germany. Eur J Clin Microbiol Infect Dis 20:452-459

6. Weigl JAI, Puppe W, Schmitt HJ (2002) The incidence of influenza-associated hospitalizations in children in Germany. Epidemiol Infect 129:525-534

7. Deutsche Gesellschaft zur Verhütung und Bekämpfung der Influenza e.V. (2001) Flu-Info 24. Woche. Abschlussbericht der Saison 2000-2001. Hannover, S 1

8. Sigurs N, Bjarnason R, Sigurbergsson F, Kjellman B (2000) Respiratory syncytial virus bronchiolitis in infancy is an important risk factor for asthma and allergy at age 7 . Am J Respir Crit Care Med 161:1501-1507

9. Dezateux C, Fletcher ME, Dundas I, Stocks J (1997) Infant respiratory function after RSV-proven bronchiolitis. Am J Respir Crit Care Med 155:1349-1355

10. Hall CB, Hall WJ, Speers DM (1979) Clinical and physiological manifestations of bronchiolitis and pneumonia. Outcome of respiratory syncytial virus. Am J Dis Child 133:798-802

11. Forster J, Tacke U, Krebs H et al. (1996) Respiratory syncytial virus infection its role in aeroallergen sensitization during the first two years of life. Pediatr Allergy Immunol 7:55-60

12. Isaacs D (1998) Is bronchiolitis an obsolete term? Current Opin Pediatr 10:1-3

13. Heiskanen-Kosma T, Korppi M (2000) Serum Creactive protein cannot differentiate bacterial and viral etiology of community-acquired pneumonia in children in primary healthcare settings. Scand J Infect Dis 32:399-402

14. Gröndahl B, Puppe W, Hoppe A et al. (1999) Rapid identification of nine microorganisms causing acute respiratory tract infections by single-tube multiplex reverse transcriptionPCR: feasibility study. J Clin Microbiol 37:1-7

15. Puppe W, Weigl JAl, Aron $G$ et al. (submitted) Evaluation of a multiplex reverse transciptase PCR ELISA for the detection of nine respiratory tract pathogens.J Clin Microbiol

16. Zambon M (2002) The use of molecular methods for diagnosis and surveillance of respiratory viruses. Abstract S308. Programm 12th European Congress of Clinical Microbiology and Infectious Diseases, Mailand, 24-27. April 2002, p 49 
17. Ghaffar F, Friedland IR, McCracken GH (1999) Dynamics of nasopharyngeal colonization by Streptococcus pneumoniae. Pediatr Infect Dis J 18:638-646

18. Weigl JAI, Puppe W, Gröndahl B, Schmitt HJ (2000) Epidemiological investigation of nine respiratory pathogens in hospitalized children in Germany using multiplex reverse transcriptase polymerase chain reaction. Eur J Clin Microbiol Infect Dis 19:336-343

19. Glezen WP (1996) Emerging infections: pandemic influenza. Epidemiol Rev 18:64-76

20. Reichert TA, Sugaya N, Fedson DS et al. (2001) The Japanese experience with vaccinating schoolchildren against influenza. N Engl J Med 344:889-896

21. Nicholson KG (1996) Impact of influenza and respiratory syncytial virus on mortality in England and Wales from January 1975 to December 1990. Epidemiol Infect 116:51-63

22. Weigl J (2002) Epidemiologie der Influenza bei Kindern. In: Schmitt HJ (Hrsg) Alte und neue Impfstoffe in Deutschland Grundlagen für künftige Entscheidungen ,I, Waldhausen II". Verlag Infomed Medizinische Verlagsgesellschaft mbH, Berlin, S51-61

23. Chin J (2000) 1. Influenza. 2. Respiratory disease, acute, viral. In: Chin J (ed) Control of communicable diseases Manual, 17. Aufl. American Public Health Association, Washington, pp 270-276, 424-430

24. Weigl JAI, Puppe W, Schmitt HJ (2002) Seasonality of respiratory syncytial virus-positive hospitalizations in children in Kiel, Germany, over a 7 year period. Infection 30:186-192

25. Weigl JAl, Puppe, W, Rockahr S, Schmitt HJ (2002) Burden of disease in hospitalized RSV-positive children in Germany. Klin Pädiatr 214:334-342

26. Weigl JAl, Puppe W, Schmitt HJ (2002) Can respiratory syncytial virus etiology be diagnosed clinically? A hospital-based case-control study in children under two years of age. Eur J Epidemiol (in press)

27. Berner R, Schwoerer F, Schumacher RF et al. (2001) Community and nosocomially acquired Respiratory Syncytial Virus infection in a German pediatric hospital from 1988 to 1999. Eur J Pediatr 160:541-547

28. Schauer U, Rieger CHL (2002) Behandlung von Kindern mit RSV-Infektionen: Eine retrospektive Analyse der Saison 1998/99. Klin Pädiatr 214:37-40

29. Waris M (1991) Pattern of respiratory syncytial virus epidemics in Finland: two-year cycles with alternating prevalence of group $A$ and $B$. $J$ Infect Dis 163:464-469

30. Hall CB (2000) Respiratory syncytial virus. In: Mandell GL, Bennett JE, Dolin R (eds) Principles and practice of infectious diseases, Vol 2, 5 th edn. Churchill Livingstone, Philadelphia, pp 2084-2111
31. Behrendt CE, Decker MD, Burch DJ et al. (1998) International variation in the management of infants hospitalized with respiratory syncytial virus. Eur J Pediatr 157:215-220

32. Laurichesse H, Dedman D, Watson JM, Zambon MC (1999) Epidemiological features of parainfluenza virus infections: laboratory surveillance in England and Wales, 1975-1997. Eur J Epidemiol 15:475-484

33. Glezen WP (1990) Morbidity associated with the major respiratory viruses. Pediatr Ann 19:535-542

34. Karron RA, O'Brien KL, Froehlich JL, Brown VA (1993) Molecular epidemiology of a parainfluenza type 3 outbreak on a pediatric ward. J Infect Dis 167:1441-1445

35. Echevarria JE, Erdman DD, Meissner HC, Anderson L (2000) Rapid molecular epidemiologic studies of human parainfluenza viruses based on direct sequencing of amplified DNA from a multiplex RT-PCR assay.J Virol Methods 88:105-109

36. Lindquist SW, Darnule A, Istas A, Demmler GJ (1997) Parainfluenza virus type 4 infections in pediatric patients. Pediatr Inf Dis J 16:34-38

37. Izurieta HS, Thompson WW, Kramarz P et al. (2000) Influenza and the rates of hospitalization for respiratory disease among infants and young children. N Engl J Med 342:232-239

38. Moriuchi $\mathrm{H}$, Katsushima N, Nishimura $\mathrm{H}$ et al. (1991) Community-acquired influenza C virus infection in children.J Pediatr 11:235-238

39. Papadopoulos NG (2001) The rhinovirus not such an innocent? Q J Med 94:1-3

40. Papadopoulos NG, Bates PJ, Bardin PG et al. (2000) Rhinovirus infect the lower airways. $J$ Infect Dis 181:1875-1884

41. McMillan JA, Weiner LB, Higgins AM, Macknight K (1993) Rhinovirus infection associated with serious illness among pediatric patients. Pediatr Infect Dis J 12:321-325

42. Chidekel AS, Rosen CL, Bazzy AR (1997) Rhinovirus infection associated with serious lower respiratory illness in patients with bronchopulmonary dysplasia. Pediatr Infect Dis J 16:43-47

43. Ruuskanen 0 (1999) Diagnosis and clinical picture of respiratory virus infections. (S-9). In: ESPID '99 Abstract Book of the 17th Annual Meeting of the European Society for Paediatric Infectious Diseases (Heraklion), p 21

44. Gwaltney JM Jr (1997) Rhinoviruses. In: Evans AS, Kaslow RA (eds) Viral infections in humans. Epidemiology and control. Plenum Medical Book Company, New York, London, pp 815-838

45. Rotbart HA, Sawyer MH, Fast S, Lewinski C et al. (1994) Diagnosis of enteroviral meningitis by using PCR with a colorimetric microwell detection assay.J Clin Microbiol 32:2590-2592

46. Horwitz MS (1996) Adenoviruses. In: Fields BN, Knipe DM, Howley PM et al. (eds) Fields virology, Vol 2.Lippincott-Raven Publishers, Philadelphia, pp 2149-2171

47. Van den Hoogen BG, de Jong JC, Groen J et al. (2001) A newly discovered human pneumovirus isolated from young children with respiratory tract disease. Nat Med 7:719-724
48. Stockton J, Stephenson I, Fleming D, Zambon M (2002) Human metapneumovirus as a cause of community-acquired respiratory illness. Emerg Infect Dis 8:897-901

49. Hall CB, Kopelman AE, Douglas RG Jr et al. (1979) Neonatal respiratory syncytial virus infection. N Engl J Med 300:393-396

50. Leclair JM, Freeman J, Sullivan BF et al. (1987) Prevention of nosocomial infection with respiratory syncytial virus infections through compliance with glove and gown isolation precautions. N Engl J Med 317:329-334

51. Krasinski K, LaCouture R, Holzman RS et al. (1990) Screening for respiratory syncytial virus and assignment to a cohort at admission to reduce nosocomial infections.J Pediatr 116:894-898

52. Madge P, Paton JY, McColl JH, Mackie PLK (1992) Prospective controlled study of four infection control procedures to prevent nosocomial infection with respiratory syncytial virus. Lancet 340:1079-1083

53. Forster J, Schumacher RF (1995) The clinical picture presented by premature neonates infected with respiratory syncytial virus. Eur J Pediatr 154:901-905

54. Simon A, von Chamier G, Eis-Hübinger AM, Exner M (1999) Nosokomiale Infektionen mit Respiratory Syncytial Virus in der Pädiatrie Vorkommen, Primärprävention, krankenhaushygienischer Standard. Hyg Med 10:410-420

55. Forster J, Adam D, Berner R, Scholz H (2001) Prophylaxe von bedrohlichen RSV-Erkrankungen durch Palivizumab. Kinder- und Jugendarzt 32:44-45

56. Weigl JAI, Puppe W, Schmitt HJ (2001) Evidence for the validity of the DGPI recommendation on palivizumab. Infection 29 [Suppl 1]:34-35

57. The Impact-RSV study group (1998) Palivizumab, a humanized respiratory syncytial virus monoclonal antibody, reduces hospitalization from respiratory syncytial virus infection in high-risk infants. Pediatrics 102:531-537 